\title{
LA NUEVA ECONOMÍA DEL SIGLO XXI: ANÁLISIS DE LOS IMPACTOS DE LA INFORMÁTICA EN EL AMBIENTE. TENDENCIAS ACTUALES EN TECNOLOGÍAS INFORMÁTICAS VERDES, UN COMPROMISO CON LA SUSTENTABILIDAD
}

Adriana Margarita Porcelli ${ }^{1}$

Adriana Norma Martínez ${ }^{2}$

\begin{abstract}
Resumen
Los grandes avances tecnológicos producidos en las últimas décadas han generado profundos cambios sociales y organizativos en el ámbito de la información y las comunicaciones que inciden en nuestras vidas. La generalización en el uso de las computadoras, la proliferación de redes informáticas y el desarrollo de las nuevas tecnologías de la información y comunicación, denominadas TICS, cambiaron la manera de comunicarnos y transformaron la economía y la cultura para siempre, originando un sistema económico y social en el que la generación, procesamiento y distribución del conocimiento y la información son la principal fuente de la productividad, poder y prosperidad. La informática y la industria en general no han ahorrado esfuerzos para desarrollarse rápidamente, pero en la mayoría de los casos, a costa del deterioro ambiental. Sin embargo, las TICS pueden ser un aliado en la lucha contra el cambio climático a través de procesos denominados Tecnologías Verdes, que se inscriben en el concepto de economía verde como contexto del desarrollo sustentable, conforme al documento final de Río +20 . El presente trabajo detallará la incidencia de la informática en los diferentes ámbitos y describirá, en términos generales, cada uno de los métodos y productos informático ecológicos
\end{abstract}

Palabras Claves: Nueva Economía - Sociedad de la Información - Ambiente - Desarrollo Sustentable Tecnologías Verdes

\section{INTRODUCCIÓN}

La innovación tecnológica es uno de los factores esenciales para aumentar la productividad que se necesita para alcanzar un crecimiento económico sostenido. La Nueva Economía, respaldada en las Tecnologías de la Información y la Comunicación posee enormes posibilidades para acrecentar el acceso a una educación de calidad, favorecer la alfabetización y la educación primaria universal respetando la diversidad cultural y lingüística,

\footnotetext{
1 Procuradora (UBA) Magíster en Relaciones Internacionales (Universidad Maimónides) Investigadora y Profesora Adjunta Ordinaria de Derecho Internacional Privado, de Derecho Internacional Público, de Estudio de la Constitución Nacional y de los Derechos Humanos y de Legislación Sanitaria. Miembro de las Comisiones de Plan de Estudio de diferentes Carreras y del Comité Académico de Bioética. (UNLu.).E-mail: adporcelli@yahoo.com.ar

${ }^{2}$ Posgraduada Derecho del Turismo, Magister en Ambiente Humano. Jefe División Derecho, Departamento Ciencias Sociales UNLu Profesora asociada UNLu. Profesora adjunta Facultad de Derecho UBA. Profesora de posgrado UNCOMA, UNLa, UNLZ, UCA y UP. Profesora visitante Universidad Complutense, Madrid, Málaga. E-mail: info@anmart.com.ar vol. 08, nº. 04, Número Especial. Rio de Janeiro, 2015.pp. 2174-2208 
siendo un instrumento eficaz para promover la paz, la seguridad y la estabilidad, así como la democracia, la cohesión social, la buena gobernanza y el estado de derecho, en los planos regional, nacional e internacional.

A partir de la Declaración del Milenio de las Naciones Unidas durante la clausura de la Cumbre del Milenio del 8 de septiembre del 2000, esa Organización identificó que, junto con los graves problemas a los que dedicaría en las sendas cumbres, como el agua y la salud y la pobreza, la humanidad había creado un área de oportunidad, el uso inteligente y apropiado de las tecnologías de información y comunicación, para dar paso a una evolución global hacia la Sociedad de la Información, como una etapa positiva de la misma.

De esta manera comenzó la preparación para la Cumbre Mundial sobre la Sociedad de la Información, CMSI, con un proceso de discusión global de cuatro años de duración, 2001-2005. En el marco de esta Cumbre dos términos ocuparon el escenario: Sociedad de la Información, y Sociedad del Conocimiento, con sus respectivas variantes. El concepto de sociedad de la información está vinculado a la idea de la innovación tecnológica, en cambio el concepto de sociedad del conocimiento incluye la transformación en la dimensión social, cultural, económica, política e institucional donde los medios o tecnologías de la información y comunicación constituyen los mecanismos para que el saber humano se pueda generar, intercambiar, compartir o conocer ampliamente entre todos las personas del mundo y la entrada en la sociedad de la información, es un paso previo a la del conocimiento. Lo fundamental no es "información" sino "sociedad" ya que la primera hace referencia a datos, canales de transmisión y espacios de almacenamiento, mientras que la segunda habla de seres humanos, de culturas, de formas de organización y comunicación. La información se determina en función de la sociedad, y no a la inversa

Sin embargo, en la última década sociedad de la información es sin duda la expresión que se ha consagrado, porque fue escogida para el nombre de la Cumbre Mundial realizada en dos fases: la primera de dos años de duración y culminó con la primera reunión cumbre realizada en Ginebra en diciembre de 2003; y la segunda, también de dos años, finalizó con la reunión de Túnez en noviembre de 2005.

El Informe Mundial de la Organización de las Naciones Unidas para la Educación, la Ciencia y la Cultura (UNESCO) titulado "Hacia las Sociedades del Conocimiento ${ }^{3}$ alude a sociedades, en plural, lo que no se debe al azar, sino a la intención de rechazar la unicidad de un modelo listo para usar, que no tenga en cuenta la diversidad cultural y lingǘstica. Hay diferentes formas de conocimiento y cultura que intervienen en la construcción de las sociedades, no se puede admitir que la revolución de las tecnologías de la información y la comunicación nos conduzca a una forma única de sociedad posible sino que significa sólo un instrumento para la realización de auténticas sociedades del conocimiento ya que la información es efectivamente un instrumento del conocimiento, pero no es el conocimiento en sí.

${ }^{3}$ UNESCO Informe Mundial Hacia las Sociedades del Conocimiento, Ediciones UNESCO: París, 2005, ISBN 92-3-304000-3. vol. 08, nº. 04, Número Especial. Rio de Janeiro, 2015.pp. 2174-2208 
Conforme la Declaración de Principios de la Cumbre Mundial sobre la Sociedad de la Información "Construir la Sociedad de la Información: un desafío global para el nuevo milenio", Ginebra 2003, cuyos términos fueron reiterados en el Compromiso de Túnez 2005, la Sociedad de la Información debe caracterizarse por la inclusión, la equidad, la accesibilidad, la participación y el pluralismo y estar centrada en la persona, integradora y orientada al desarrollo sostenible y en la mejora de su calidad de vida. ${ }^{4}$ Sin embargo, se admite que la brecha digital es uno de los principales obstáculos en este modelo de desarrollo, al que se puede agregar que en cuestiones ambientales el costo del desarrollo tecnológico puede llegar a ser demasiado alto y la informática una de las industrias que más contaminación produce.

En consecuencia, las tecnologías de la información y comunicación son hoy una pieza fundamental y pueden convertirse en aliadas en la lucha contra el cambio climático y sus impactos negativos, que afectan a todos los Estados y debilitan su capacidad en general, y la de los países en desarrollo en particular, para el logro del desarrollo sustentable, a través de procesos denominados Tecnologías Verdes, Green IT, Green Computing, que se inscriben en el concepto de economía verde como contexto del desarrollo sustentable, en pos de la erradicación de la pobreza, y marco institucional para la sustentabilidad, tal como lo propugna el documento final de Río + 20.

El presente trabajo se encuentra estructurado en tres partes: la primera describirá, a grandes rasgos, las características de la denominada nueva economía, la segunda especificará la incidencia de la informática en los diferentes ámbitos y la tercera enumerará, en términos generales, cada uno de los métodos propuestos y productos informático ecológicos.

\section{LA NUEVA ECONOMÍA}

El término nueva economía fue acuñado por el economista Brian Arthur, popularizado principalmente por Kevin Kelly, en su libro Nuevas reglas para la nueva economía, para describir el nuevo cambio en la economía, que anteriormente se basaba en la industria, comercio y fabricación, y que ahora dio paso a una economía basada fundamentalmente en el conocimiento, gracias a factores tales como el desarrollo tecnológico y la globalización. Conforme las palabras de CASTELLS $(2000)^{5}$, la expresión nueva economía es un término consagrado en los medios de comunicación que, no significa una nueva economía sino otro tipo de economía, que es en la que estamos actualmente, no es el futuro, es el presente, y no es América, se desarrolla de forma desigual y contradictoria, pero que se desarrolla en todas las áreas del mundo

La nueva economía se caracteriza fundamentalmente por tres grandes rasgos interrelacionados:

${ }^{4}$ CMSI Cumbre Mundial de la Sociedad de la Información. Declaración de Principios "Construir la Sociedad de la Información: un desafío global para el nuevo milenio” Documento WSIS-03/GENEVA/4-S, Ginebra 2003 - Túnez 2005, 12 de mayo de 2004

${ }^{5}$ CASTELLS, Manuel. “La Ciudad de la Nueva Economía”. Revista La Factoría, Barcelona, Año XV, № 12 Junio-septiembre 2000. Manuel Castells es profesor de la Universidad de Berkeley, palabras vertidas en el acto de clausura del Máster "La ciudad: políticas proyectos y gestión" organizado por la Universidad de Barcelona 
1. La economía del conocimiento: es una economía que está centrada en el conocimiento y en la información, en la capacidad de generación y procesamiento de información y en la transformación de esa información en conocimiento adecuado a las tareas necesarias para la economía como base de la producción, productividad y competitividad, tanto para empresas como para regiones y países

2. Una economía global: en segundo lugar, global significa que las actividades económicas dominantes están articuladas globalmente y funcionan como una unidad en tiempo real, y en torno a dos sistemas de globalización económica: la globalización de los mercados financieros interconectados en todas partes, por medios electrónicos y, por otro lado, la organización a nivel planetario de la producción de bienes y servicios y de la gestión de estos bienes y servicios. La internacionalización del comercio es en realidad una función de la internacionalización de la producción, es decir: más que exportar, lo que se está haciendo es producir internacionalmente, por cuanto lo que se ha internacionalizado es la producción.

3. Empresa red: la tercera característica, indispensablemente ligada a estas otras dos, es el funcionamiento en redes de esta nueva economía, en redes descentralizadas dentro de la empresa y en redes entre las empresas y sus redes de pequeñas y medias empresas subsidiarias. Esa empresa en red es hoy en día de tal complejidad que sólo puede funcionar gracias a las nuevas tecnologías de comunicación y fundamentalmente de Internet. Internet es la base material en la que puede trabajar la empresa en red. Ahora bien, Internet, sin la transformación organizativa de una empresa flexible en redes de todo tipo, no

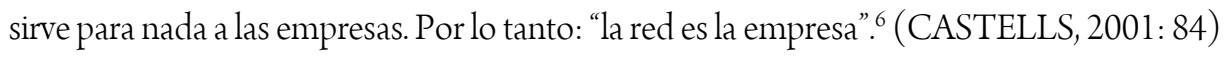

La nueva economía no es sólo una economía del conocimiento, es una economía algo más compleja, tiene una base tecnológica, de información y comunicación y una forma central de organización cada vez mayor, que es Internet. El equivalente de Internet en la era industrial era la fábrica: lo que era la fábrica en la era industrial, es Internet en la era de la información y esa economía no ha hecho más que empezar, en lugar de haberse terminado y conlleva a la formulación de una nueva caracterización de bienes: los digitales, intangibles que, a diferencia de los bienes materiales, se los define como no antagónicos, lo que significa que mucha gente pueda hacer uso de esos bienes sin que nadie tenga que renunciar a ellos. Esto último va unido en forma indisoluble con las nuevas maneras de procesar, almacenar y transferir información. Concordantemente, señala RIFKIN: " el carácter físico de la economía se reduce. Si la era industrial se caracterizaba por la acumulación de capital y de propiedad física, en la nueva era lo estimable son las formas intangibles de poder que se presentan en paquetes de información y en activos intelectuales" ( RIFKIN, 2000:20)

\section{IMPACTOS DE LA INFORMÁTICA EN LOS DIFERENTES SECTORES}

\footnotetext{
${ }^{6}$ CASTELLS, Manuel. La Galaxia Internet, España: Areté, 2000, p.84

${ }^{7}$ RIFKIN, Jeremy. La Era del Acceso: La Revolución de la Nueva Economía, Barcelona: Paidós, 2000, p.20 vol. 08, nº. 04, Número Especial. Rio de Janeiro, 2015.pp. 2174-2208
} 
La informática es el conjunto de conocimientos científicos y técnicas que hacen posible el tratamiento automático de la información por medio de computadoras. Por tanto, se entiende por informática -palabra formada por la asociación de términos INFOrmación y automática- al conjunto de métodos y mecanismos que tienen como objeto el tratamiento racional y automático de la información, Se compone de un "contenido", asociado al software, y de una forma o "soporte", el hardware. En cambio, se define tecnología como conjunto de teorías y de técnicas que permiten el aprovechamiento práctico del conocimiento científico. Por ello, la tecnología existe para distintos conocimientos científicos, no solo el informático.

Por su parte, ambiente y desarrollo, en este caso el tecnológico informático, no constituyen desafíos separados; están inevitablemente interligados ya que el desarrollo no se mantiene si la base de recursos ambientales se deteriora. A su vez, el concepto de desarrollo sostenible o sustentable apunta a que la calidad de vida de la generación presente, como bien jurídico tutelado, se alcance sin comprometer la capacidad de las generaciones futuras, de lo que se desprende que el ser humano, individual y colectivamente, es responsable del futuro del planeta

En consecuencia los impactos negativos que pueden generar los sistemas informáticos ${ }^{8}$ y tecnológicos deben ser identificados y evaluados desde un primer momento con el objeto de desarrollar una conciencia social y ambiental tanto a nivel personal como colectivo. Tal actividad debe estar orientada en lo posible a evitar, o al menos minimizar, los impactos causados por este tipo de tecnologías. Esos impactos se pueden clasificar conforme los siguientes ámbitos: ambiental, económico, visual, social y de salud

\section{Impacto Ambiental}

\section{Procesos de fabricación contaminantes}

La fabricación de computadoras y varios de sus componentes electrónicos o no electrónicos es un sector muy contaminante, con sustancias tóxicas tales como dioxinas, cadmio y plomo, además de consumir electricidad, materias primas, sustancias químicas y agua generando residuos nocivos para la salud. Todo esto incrementa las emisiones de dióxido de carbono $\left(\mathrm{CO}_{2}\right)$ e impacta de forma directa o indirecta en el ambiente. El proceso de la fabricación de PCs y otros sistemas vinculados con las tecnologías de la comunicación -desde teléfonos móviles a pantallas y puertos USB- es junto con el de su reciclado, uno de los más costosos desde el punto de vista ambiental. Por su parte, el berilio ha sido recientemente considerado un elemento cancerígeno para el ser humano. La mayor parte de este mineral es usado en aleaciones (mezclas de metales) para la fabricación de componentes eléctricos o electrónicos, o como materiales para la construcción de maquinarias, automóviles y

\footnotetext{
${ }^{8}$ Se denomina equipo informático al conjunto de aparatos y dispositivos que constituyen el material de una computadora vol. 08, nº. 04, Número Especial. Rio de Janeiro, 2015. pp. 2174-2208
} 
computadoras. En Estados Unidos, tanto el Departamento de Salud y Servicios Humanos (DHHS) como la Agencia Internacional para la Investigación del Cáncer (IARC, por sus siglas en inglés) han determinado en el Capítulo Reseña Toxicológica del Berilio de los Resúmenes de Reseñas Toxicológicas, 2002, que el berilio y sus compuestos son carcinogénicos en seres humanos ${ }^{9}$

\section{$\underline{\text { Residuos o desechos electrónicos: obsolescencia de equipos y programas }}$}

En la actualidad tanto el sistema de cómputo como sus componentes contienen materiales tóxicos y los consumidores se deshacen de los viejos CPUs, monitores u otro equipamiento electrónico dos o tres años después de su compra. Es más, hasta hace unos años el uso promedio de una computadora era de tres años, en la actualidad la misma se puede volver obsoleta al año de su compra, y gran cantidad de estos componentes terminan contaminando la tierra y, en muchos casos, el agua ${ }^{10}$

Aun durante este periodo de vida útil, es muy probable que sea necesario realizar actualizaciones de componentes en las máquinas, tanto referidas al hardware ${ }^{11}$ como al software ${ }^{12}$. El proceso de desarrollo de software es un proceso de elaboración que consiste en transformar una cosa u obtener un producto por medio del trabajo correspondiente o la invención o idea de algo complejo. Con el correr del tiempo, el software puede sufrir modificaciones correctivas, vinculadas a corregir errores; adaptativas, relacionadas con adaptar el software a nuevas formas de operar; y ampliaciones, relacionadas con el agregado de nuevas funcionalidades, que al modificar el código y documentación inicial van deteriorando su correcto funcionamiento.

Toda esta producción tecnológica genera toneladas de basura electrónica, también denominado internacionalmente E-Waste (del inglés electronic waste). En Europa también es conocido como RAEE, residuos de aparatos electrónicos y eléctricos, con la diferencia que esta sigla incorpora a los residuos eléctricos. El E-Waste se refiere a todo producto, bien o componente que posee un dispositivo electrónico o chip, que ha llegado al término de su vida útil y está asociado a aparatos que utilizamos diariamente y en distintos lugares: por ejemplo en el hogar: computadores, monitores, mouse, teléfonos móviles, calculadoras, juegos de video, cargadores de teléfonos móviles, entre otros; en la oficina: equipos de fax, impresoras, fotocopiadoras, proyectores, escáner,

\footnotetext{
9 ATSDR. Agencia para Sustancias Tóxicas y el Registro de Enfermedades. Reseña Toxicológica del Berilio. Atlanta, GA: Departamento de Salud y Servicios Humanos de EE. UU., Servicio de Salud Pública, 2002

10 “Tecnología para cuidar el Medio Ambiente" Revista Claves 21 Ambiente y Desarrollo Sustentable [Consulta: 20/05/20 15] Disponible en: <http://claves21.com.ar/tecnologia-verde-herramientas-para-cuidar-el-medio-ambiente/>

${ }^{11}$ El Hardware, es un bien tangible, es el conjunto de los componentes que integran la parte material de una computadora proviene del inglés hard, duro, es decir, la parte dura, material y concreta del sistema, son los componentes o dispositivos físicos, es todo lo que se puede ver y tocar.

${ }^{12}$ La palabra software que proviene del inglés soft o blando representa la lógica del sistema, las reglas de su funcionamiento Según el Institute of Electrical and Electronics Engineers - IEEE, el software consiste en un programa, datos y documentación, es decir, el software es todo lo intangible y abarca además del programa en sí, los datos o estructuras de datos que el mismo va a utilizar y la documentación asociada
} 
centrales telefónicas y en la industria: además de todos los anteriores, equipos de telecomunicaciones, equipos médicos, sistemas microondas y baterías, sistemas de audio y sistemas de seguridad. De acuerdo a la definición de la OCDE, se considera residuo electrónico "todo aparato que utiliza un suministro de energía eléctrica y que ha llegado al fin de su vida útil” (OCDE, 2001).

La producción de aparatos electrónicos requiere una amplia y compleja combinación de sustancias, tales como plomo, mercurio, berilio, selenio, cadmio, cromo y metales preciosos cuya extracción y transformación contaminan enormemente. El impacto en el ambiente comienza desde la etapa de fabricación, debido también a la cantidad de energía que se emplea. La cantidad de residuos generados para producir una unidad, denominado la "carga ecológica" de un computador es casi 1.500 kilogramos, de un portátil, 400 kilogramos y de un teléfono móvil, 75 kilogramos ${ }^{13}$

En el año 2002, la Red de Acción de Basilea, BAN, difundió un demoledor reporte titulado " Exporting Harm: The High-tech Trashing of Asia ", que mostraba la cruda realidad del reciclaje de la basura electrónica en China. La ciudad de Guiyu, cercana a Hong Kong, se había convertido en un gigante vertedero de basura informática en el cual miles de personas, muchas de ellas niños y ancianos, realizaban prácticas peligrosas como quemar los cables de los ordenadores para obtener el cobre, o fundir circuitos en un cazo sobre el fuego para recuperar el plomo y otros metales. Estudios realizados en esta ciudad han mostrado que en el área de Guiyu se dan los más altos niveles del mundo de dioxinas que se relacionan con el cáncer, que es seis veces más probable que los embarazos terminen en abortos y que en siete de cada diez niños tienen se detecte plomo en sangre. Pese a que en 2000 China prohibió específicamente la importación de residuos electrónicos, esta norma no ha impedido el ingreso de estos desechos, si bien tras la difusión del impactante documental, las autoridades chinas presionaron para el cumplimiento de esta prohibición ${ }^{14}$

En la mayoría de los países de la Unión Europea se aplica el principio de responsabilidad extendida del productor (REP); definida como un "principio de política ambiental que promueve el mejoramiento total del ciclo de vida de los productos, por medio de la extensión de las responsabilidades del productor en varias etapas de dicho ciclo, especialmente al devolver, recuperar y disponer el producto" (LINDHQVIST, 2000) ${ }^{15}$. Se sostiene que este mecanismo induce a los proveedores a diseñar productos menos contaminantes y que, a su vez, faciliten el reciclado. Se estima que impacta en el precio de los PC en aproximadamente 60 dólares (de acuerdo a datos publicados por la consultora Gartner). En igual sentido, en China, en agosto de 2008 se aprobó una norma que

\footnotetext{
${ }^{13}$ RECYCLA, CHILE. Residuos electrónicos (E-WASTE), la nueva basura del siglo XXI. Una Amenaza-Una Oportunidad. Santiago de Chile: RECYCLA, Chile, Fundación Casa de la Paz, 2007, p.11-12

${ }^{14}$ PUCKETT, Jim; BYSTER, Leila; WESTERVELT, Sarah; GUTIERREZ, Richard; DAVIS, Sheila; HUSSAIN, Hasma; DUTTA, Madhumitta Exporting Harm: The High-tech Trashing of Asia Seattle: BAN, SVTC 2002 p. 15-17

${ }^{15}$ SILVA, Uca. Los residuos electrónicos (RE) en la Sociedad de la Información en Latinoamérica En UNESCO. Plataforma Regional de Residuos electrónicos para América Latina RELAC. Los residuos electrónicos: Un desafío para la Sociedad del Conocimiento en América Latina y el Caribe. Montevideo: UNESCO RELAC, 2010 p.30
} 
impulsa, la responsabilidad extendida del productor en el reciclado y la disposición final del equipamiento, así como la imposición de restricciones a sustancias peligrosas en su fabricación pero que además instrumenta un plan de reciclado centralizado con financiamiento por parte del Estado ${ }^{16}$

\section{Exigencias de energía}

Los equipos de computación son aparatos que requieren de energía eléctrica para funcionar. El incremento de la utilización de tales dispositivos conlleva un aumento en las necesidades de energía y en la producción de la misma, que tendrá impacto en el requerimiento de recursos naturales. Con la creciente demanda de Centros de Datos para centralizar aplicaciones de TI, el consumo de energía ha mostrado un aumento acelerado en la última década, por lo que implementar estrategias que contribuyan a reducir tanto el consumo de energía, como los efectos perjudiciales al ambiente, es primordial.

En Estados Unidos el consumo de energía utilizada por los Data Center se calculó en más de 4,500 millones de dólares, según una encuesta publicada por Survey of the Data Center Users Group, DCUG, en 2007. Para poner el problema en perspectiva basta señalar que su consumo energético representa entre el 1,7\% y el 2,2\% del consumo eléctrico del país, el uso de energía en los centros de datos creció un 36\% en los últimos cinco años. La cantidad que consume cada servidor, no obstante, creció más rápido entre 2005 y 2010 de lo que lo hizo entre 2000 y 2005

\section{Huella de carbono}

El término huella de carbono es ampliamente utilizado como amenaza al cambio climático global. La huella de carbono es un sinónimo de emisión de dióxido de carbono u otros gases de efecto invernadero expresados en $\mathrm{CO}_{2}$. Es la medida del impacto que las actividades humanas tienen sobre el ambiente en términos de la cantidad de gases producidos, medidas en toneladas de dióxido de carbono.

La Huella de Carbono es «la totalidad de gases de efecto invernadero (GEI) emitidos por efecto directo o indirecto de un individuo, organización, evento o producto» (UK Carbon Trust 2008), y da idea de "cuánto contamina" un producto o servicio determinado. Con la huella de $\mathrm{CO}_{2}$, se pretende que las empresas puedan reducir los niveles de contaminación mediante un cálculo estandarizado de las emisiones que tienen lugar durante los procesos productivos y de esta manera los consumidores puedan optar por productos más sanos y menos contaminantes en beneficio del desarrollo humano y sustentable y la calidad de vida como bien jurídicamente

\footnotetext{
${ }^{16}$ MONTEVERDE, Federico. E-waste y su incorporación en la agenda gubernamental e internacional UNESCO Plataforma Regional de Residuos electrónicos para América Latina RELAC. Los residuos electrónicos: Un desafío para la Sociedad del Conocimiento en América Latina y el Caribe. Montevideo: UNESCO RELAC, 2010, p.219
} 
protegido. Desde este punto de vista, un producto con una HC alta sería menos amigable con el ambiente que uno de baja HC y podría dirigir al consumidor a optar por el segundo producto pensando en que está tomando una decisión que impacta positivamente sobre el Cambio Climático o el Calentamiento Global. ${ }^{17}$

\section{Impacto Social}

\section{$\underline{\text { Brecha Digital }}$}

La Sociedad de la Información además de una revolución tecnológica constituye un cambio en los modos de existir, de pensar y de relacionarnos con el mundo y con los demás. Conforme la Declaración de Principios de la IV Cumbre Mundial sobre la Sociedad de la Información Compromiso de Túnez 2005, la Sociedad de la Información debe caracterizarse por la inclusión, la equidad, la accesibilidad, la participación y el pluralismo y estar centrada en la persona, integradora y orientada al desarrollo sostenible y en la mejora de su calidad de vida, así como propiciar la democracia, la cohesión social, la buena gobernanza y el estado de derecho, en los planos regional, nacional e internacional. Sin embargo, se admite que la brecha digital es uno de los principales obstáculos en este modelo de desarrollo ya que beneficios de las tecnologías no necesariamente son destinados a elevar la calidad de vida de la mayoría de las personas. De cada nueva tecnología se desprenden beneficios para determinados sectores de la sociedad mientras que otros sectores resultan perjudicados.

El concepto de brecha digital encuentra su antecesor en el llamado informe "El eslabón perdido", que se publicó en 1982 por la Comisión Maitland, donde se evidenció la carencia de infraestructuras de telecomunicaciones en los países en vías de desarrollo, poniendo como ejemplo el teléfono. A partir de este origen, algunas otras expresiones han sido usadas para referirse a la brecha digital como divisoria digital, estratificación digital y fractura digital. El origen del concepto se remonta a la época en que se inicia el proyecto Minitel en Francia a finales de la década de los 70 y principios de los 80, el cual contempló la sustitución de los directorios telefónicos impresos por unos equipos de cómputo para buscar números telefónicos en una base de datos electrónica.

El tema a analizar es si la introducción de las nuevas tecnologías en la sociedad internacional es la causa de la existencia de la brecha digital o si en realidad la brecha es social y la causa originaria de esta disparidad tanto en lo económico, tecnológico y social es la pobreza. El informe sobre el Desarrollo Mundial de las Telecomunicaciones de la Unión Internacional de las Telecomunicaciones ${ }^{18}$ subraya que la brecha existe entre

\footnotetext{
${ }^{17}$ FARIÑA, Clara; GUARÁS, M. Daniela; HUYKMAN, Natalia; PANIZZA, Amalia; PASCALE, Carla. "Huella de Carbono: Un Tema Insoslayable”. Revista Alimentos Argentinos Buenos Aires: Ministerio de Agricultura, Ganadería y Pesca de la Nación Argentina, no 52, p. 13-15, noviembre 2011

${ }^{18}$ UIT Unión Internacional de las Telecomunicaciones. Informe sobre el Desarrollo Mundial de las Telecomunicaciones 2003: Indicadores de Acceso para la Sociedad de la Información. Ginebra: UIT, 2003
} 
países con distinto niveles de desarrollo y aún dentro de un mismo país entre diferentes zonas, entre distintas clases sociales, entre gente de distintas edades. Asimismo, sostiene Francis Fukuyama, citado por Bacher, que "la brecha no es digital sino de equidad institucional. La cuestión no es empezar por las computadoras sino empezar con el problema político básico"19 (BACHER, 2001) En consecuencia, la pobreza es el factor que impide el acceso no sólo a las tecnologías sino a la salud, a la educación y al bienestar individual y social.

En este orden de ideas, el aprendizaje basado en Internet no depende únicamente de la pericia tecnológica, lo fundamental es cambiar del concepto de aprender por el de aprender a aprender, ya que la mayor parte de la información está en Internet y lo que realmente se necesita es la habilidad para decidir qué queremos buscar, cómo obtenerlo, procesarlo y utilizarlo. En otras palabras, desarrollar la capacidad educativa para transformar la información en conocimiento y el conocimiento en acción. Como consecuencia de lo anteriormente expuesto, la brecha digital es una expresión que hace referencia a la diferencia socioeconómica multidimensional, de acuerdo a las condiciones demográficas y geográficas, el ingreso de la población y su distribución y el nivel educativo, entre aquellas comunidades que tienen acceso a los beneficios de la Sociedad de la Información y aquellas que no. El término opuesto que se emplea con más frecuencia es el de inclusión digital.

La Organización para la Cooperación y el Desarrollo Económicos define el concepto brecha digital en términos de acceso a computadoras (TIC) e internet y habilidades de uso de estas tecnologías. "El desfase o división entre individuos, hogares, áreas económicas y geográficas con diferentes niveles socioeconómicos con relación tanto a sus oportunidades de acceso a las tecnologías de la información y la comunicación, como al uso de Internet para una amplia variedad de actividades" (OCDE, 2001: 5$)^{20}$

No obstante, la propia OCDE define a la tecnología como un proceso social, lo cual torna necesario explorar un significado más amplio para este concepto. De manera general brecha digital se vincula con la idea de tener acceso a internet, concibiéndolo en tres dimensiones: la primera corresponde al llamado comercio electrónico, la segunda a la llamada sociedad de la información, en donde la red crea las condiciones de una biblioteca virtual universal, esto es, como medio de acceso a un gran acervo de información disponible a través de los sitios y se concibe como la tercera dimensión al llamado gobierno electrónico.

Sin embargo, al hablar de brecha digital se maneja el supuesto implícito de que todo ser humano al tener acceso a información formal la usa o sabe usarla pero esto no siempre es cierto, sobre todo depende del país del que se trate, de su nivel de desarrollo y costumbres culturales.

En Argentina, las conclusiones de la 16a edición del Índice de Brecha Digital de la consultora Marco Marketing Consultants, son terminantes: "En cuanto a los precios de los productos en dólares, en la Argentina se

${ }^{19}$ BACHER, Silvia. "La verdadera brecha digital", Diario La Nación, Sección Opinión 6/11/2001, Buenos Aires[Consultado el 16/3/2015] Disponible en: <http://www.lanacion.com.ar/349072-la-verdadera-brecha-digital>

${ }^{20}$ OECD Organization for Economic Cooperation and Development. Understanding the digital divide, Paris: OECD Digital Economy Papers, n 49, 2001, p. 5 
encuentran los valores más altos de todos, en cada uno de los productos seleccionados". De hecho, una notebook que en el país cuesta US\$ 1389, es $11 \%$ más barata en Brasil y en Chile, y $45 \%$ más barata en Colombia. En Estados Unidos, una notebook de características similares se consigue por sólo US\$ 634 dólares. Con los smartphones (se tomó en cuenta el precio de equipos liberados, sin planes), la diferencia entre los precios en la Argentina y en los demás países de la región es aún mayor. Aquí, el precio promedio de un teléfono de última tecnología es de US\$1129, US\$ 400 más caro que en Brasil, Chile y Perú, y US\$ 450 más costoso que en México y Colombia. La única excepción son las notebooks Pero los problemas con el acceso a la tecnología en la Argentina no se limitan a los altos precios, sino a la poca disponibilidad de bienes de última tecnología. "Frente a Brasil, Chile y México, la Argentina es el único país que no dispone de los mismos productos en cuanto a características avanzadas", dijo Ramiro Izurieta, gerente general de Marco para el Cono Sur, y aclaró que "la única excepción son los smartphones" 21

\section{$\underline{\text { Uniformidad del lenguaje }}$}

La rapidez con la que la Informática se ha esparcido, diseminado y propagado por todo el mundo con un lenguaje técnico específico, creado por unos especialistas de origen estadounidense, se ha convertido en un instrumento de masa indispensable en todo el planeta. Si se observa su evolución respecto al resto de los lenguajes especializados, el de la informática ha mantenido desde su origen un ritmo de crecimiento constante y una progresiva difusión más allá de su ámbito especializado

La Organización de las Naciones Unidas para la Educación, la Ciencia y la Cultura (UNESCO), en el 2005, publicó un informe titulado "Hacia las sociedades del conocimiento", en el cual alertó sobre la posibilidad de que las nuevas tecnologías aceleraran la extinción de algunas lenguas "endémicas", toda vez que las herramientas de interconexión propician la homogeneidad en lugar de la diversidad.

El vínculo de la desaparición de las lenguas y la uniformidad se puede ver con claridad cuando se revisan estudios relacionados con el idioma en que se encuentran la mayoría de los contenidos en Internet: el inglés es el idioma hegemónico.

Vale la pena retomar el artículo titulado "El lenguaje de la nieve", publicado por la UNESCO con motivo del Día Internacional de la Lengua Materna 2014, para poner un ejemplo específico de lo que se pierde tan sólo por asumir la uniformidad lingüística. Además, el acceso a la información, la educación, la investigación científica,

\footnotetext{
${ }^{21}$ PALLARES, José Hidalgo "Brecha digital: la tecnología en la Argentina es cara y atrasada" Diario La Nación. Buenos Aires: 23/03/2014 p.1
} 
la diversidad cultural y lingüística, que representa el verdadero desafío planteado a la edificación de las sociedades del conocimiento. ${ }^{22}$

\section{Impacto económico}

\section{Globalización}

Uno de los grandes rasgos que caracterizan a la nueva economía es la globalización, no hay una definición única sino diferentes versiones de un mismo fenómeno. En términos generales podemos afirmar que es un proceso económico, tecnológico, social y cultural a escala planetaria que consiste en la creciente comunicación e interdependencia entre los distintos países del mundo uniendo sus mercados, sociedades y culturas, a través de una serie de transformaciones sociales, económicas y políticas que les dan un carácter global. A menudo es identificada como un proceso dinámico producido principalmente por las sociedades que viven bajo el capitalismo democrático o la democracia liberal, y que han abierto sus puertas a la revolución informática En la economía, se caracteriza por la integración de las economías locales a una de mercado mundial cobrando mayor importancia el rol de las empresas multinacionales y la libre circulación de capitales junto con la implantación definitiva de la sociedad de consumo. Además de la movilidad de capital, tecnologías, recursos económicos y humanos, se puede observar una pérdida del poder de los Estados. Por su parte, SPOTA (1999) diferencia globalización de internacionalización porque esta última es un medio para posibilitar a los Estados satisfacer sus intereses nacionales en áreas en las cuales son incapaces de hacerlo por sí mismos. La internacionalización implica cooperación entre Estados soberanos mientras que la globalización está minando o erosionando la soberanía de dichos Estados ${ }^{23}$

Al hablar de "globalización" se diferencian varios niveles de significados:

1. En lo técnico, se relaciona con la implantación de nuevas tecnologías, con la elaboración y transferencia de información, uniendo regiones distantes;

2. En lo político, se relaciona con la finalización de la "guerra fría";

3. En lo ideológico-cultural, puede entenderse como la universalización de determinados modelos de valor, por ejemplo, el reconocimiento de los derechos fundamentales, democracia liberal y el modelo de consumo capitalista;

\footnotetext{
${ }^{22}$ LÁREZ, Jesús; ABAFFY, Carlos Las TIC y la Brecha Digital. 2da. Jornada de Ingeniería Informática Tecnología con sentido social, Guayana, Venezuela: UCAB, 2009.

${ }^{23}$ SPOTA, Alberto "Globalización, integración y derecho constitucional" Revista La Ley, 22/2/99, Buenos Aires vol. 08, nº. 04, Número Especial. Rio de Janeiro, 2015.pp. 2174-2208 
4. En lo económico, la liberación del tráfico de mercancías, servicios y capitales, la posición cada vez más dominante de las empresas multinacionales, el capitalismo como dominante y universal, no así la fuerza de trabajo

\section{Impacto Visual}

\section{$\underline{\text { Estructuras metálicas, cables y antenas }}$}

Instalación de redes, torres, antenas, cableado y tendido eléctrico que causan una alteración del paisaje y por ende contaminación visual. Asimismo, la instalación de cables submarinos intercontinentales causa otros impactos asociados sobre los ecosistemas y comunidades costeras.

\section{Carteles publicitarios}

Exceso de avisos publicitarios e informativos en forma de carteles en calles y rutas producto de la dinámica comercial de la industria de las telecomunicaciones. El contenido visual de este tipo de mensaje publicitario es extremadamente atractivo, por ende produce un alto índice de distracción aumentando el riesgo de accidentes. Todos estos factores afectan negativamente a nuestro cerebro que cede ante estas presiones provocándonos dolor de cabeza, estrés, o distracción.

\section{Impacto en la Salud}

Antes de enumerar los efectos negativos, como todavía no existe certeza científica es necesario recordar el principio de precaución, que comenzó a aparecer en instrumentos legales internacionales a mediados de los años ochenta, aunque, previamente, había estado presente como principio en ordenamientos legales locales, más notablemente en Alemania del Oeste.

El principio 15 de la Declaración de Río de Janeiro de la Conferencia de las Naciones Unidas sobre Medio Ambiente y Desarrollo (1992), refleja la importancia de este principio, en los casos en que haya peligro de daño grave o irreversible, la falta de certeza científica absoluta no deberá utilizarse como razón para postergar la adopción de medidas eficaces en función de los costos para impedir la degradación del ambiente.

La Organización Mundial del Comercio, en el Módulo de capacitación sobre el acuerdo de medidas fitosanitarias afirma que el "principio de precaución" es un concepto que respalda la adopción de medidas protectoras antes de contar con una prueba científica completa de un riesgo; es decir, no se debe posponer una medida por el simple hecho de que no se disponga de una información científica completa. En la actualidad estamos viviendo una serie de procesos tecnológicos e industriales sin precedentes, de cuyos efectos no tenemos 
suficiente información. Es importante profundizar en los aportes de este principio para evitar daños irreversibles en el ambiente y en la salud de los seres humanos por la falta de certeza científica completa.

\section{Contaminación electromagnética}

Todo aparato de tipo eléctrico o electrónico aporta radiación en forma de campo electromagnético en mayor o menor grado y, si bien muchos de ellos generan niveles de radiación que están por debajo de los niveles máximos permitidos, otros los sobrepasan por sus altas intensidades, lo que se agrava por el hecho que, en muchos casos, las personas están expuestas a ellos sin ningún tipo de protección y durante períodos muy prolongados de tiempo. Los problemas que pueden provocar son dolores de cabeza, cansancio, estrés, problemas de la visión, nerviosismo, irritabilidad, insomnio; alteraciones cardiovasculares y gástricas.

\section{$\underline{\text { Ionización positiva }}$}

Existe una gran cantidad de elementos y situaciones que vician el aire y que, sobre todo, reducen de forma alarmante la concentración de iones negativos, altamente favorables para la salud. Algunos ejemplos típicos de estas situaciones y/o elementos se encuentran a menudo en locales frecuentados por un gran número de personas, el empleo del aire acondicionado, la calefacción, los terminales de video, la televisión, las computadoras y en mayor medida los pararrayos radiactivos, las centrales nucleares, las líneas de alta tensión, los transformadores, el uso de materiales sintéticos y fibras que generan grandes cargas electrostáticas y las instalaciones eléctricas de las edificaciones.

\section{Enfermedades de las nuevas tecnologías}

Los avances tecnológicos además de facilitar las tareas diarias y ahorrar tiempo, también pueden producir enfermedades, traumas o padecimientos físicos o psicológicos entre los que podemos mencionar: estrés visual se lo define como la inhabilidad de la persona para procesar determinada información visual de una manera confortable y eficiente; tensión cervical: el dolor en los síndromes cervicales a veces se irradia al hombro y brazo; epicondilitis humeral: similares al codo del tenista, relacionado con el tiempo de trabajo y síndrome del túnel carpiano, del nervio mediano: en el antebrazo se presentan las neuropatías causadas por actividades desarrolladas en posturas no neutrales de la articulación de la muñeca ${ }^{24}$

\footnotetext{
${ }^{24}$ MANERO ALFERT, Rogelio; MICHEVA, Lilian.; PETKOVA, Iveta. "Respuestas fisiológicas de hombres y mujeres a diferentes cargas de trabajo”, Revista Cubana de Investigaciones Biométricas, Cuba, Vol. 3, p. 11- 21, enero/abril 1984. 


\section{MÉTODOS Y PRODUCTOS TECNOLÓGICOS PROPUESTOS: TECNOLOGÍA VERDE E INFORMÁTICA VERDE, GREEN IT, GREEN COMPUTING Y AMBIENTE}

A medida que nuestra vida se digitaliza e Internet cambia desde la forma de ver la televisión hasta la operatoria bancaria, se advierten los efectos contaminantes de la informática. Según un informe realizado por analistas tecnológicos de la consultora McKensey, las tecnologías de la comunicación Information and Communication Technology, ICT por sus siglas en inglés, son responsables de:

1. Un $2,9 \%$ de las emisiones de dióxido de carbono $\left(\mathrm{CO}_{2}\right)$ mundiales, proyectando, para el año 2020 que esta cifra podría subir hasta el 3\%, lo que equivaldría a, por ejemplo, dos veces las emisiones actuales de un país como Reino Unido. Esta cifra las situaría al mismo nivel que las emisiones de la industria de la aviación.

2. El $60 \%$ de los data center se están quedando sin energía, refrigeración y espacio para alojar más servidores y en algunos resulta complicado refrigerar tantos sistemas en tan poco espacio. Los Data Centers que usan modelos anticuados de interacción programa a programa y de compartición de datos, que no se han actualizado mediante modelos de consolidación y virtualización, padecen un incremento de almacenamiento de información año tras año, lo cual provoca que muchas organizaciones cuenten con una cantidad elevada de servidores y otros activos que se traduce en falta de espacio físico para mantenerlo operativo

3. El $70 \%$ de los residuos de plomo y mercurio en los vertederos proviene de residuos electrónicos

4. La electricidad consumida por los Centros de Procesos de Datos (CPD's) representa el equivalente a la emisión anual de 170 millones de toneladas de $\mathrm{CO}_{2}$ a la atmósfera. Esta energía tiene su origen generalmente en "centrales" donde se realiza la combustión de materiales de origen fósil, y éstas sí son las fuentes principales de contaminación atmosférica. Consecuentemente, las TIC se convierten de forma indirecta en una fuente de emisión de gases con una elevada huella de carbono ${ }^{25}$.

Sin embargo las emisiones de carbono no se originan solamente en el campo de la utilización de las tecnologías de la hiper información y comunicación, sino que también existen otros campos que por su naturaleza y dinámica también emiten un valor importante en materia de emisión de carbono, como lo es el asociado con el transporte de carretera, la aviación nacional, el transporte marítimo, la industria, los comodities, la agricultura y algunos residuos generales. En este sentido, los seis gases de efecto invernadero que regula el Protocolo de Kioto, recogidos en su Anexo A, con potencial de calentamiento global son los siguientes:

\footnotetext{
${ }^{25}$ MUÑOZ GINER, Javier; ROJAS RINCÓN, Yuresky. "Nuevas tendencias en tecnologías verdes -Green IT para la Gestión en Organizaciones” II Congreso Iberoamericano SOCOTE - Soporte al Conocimiento con la Tecnología- y VII Congreso SOCOTE Universidad Politécnica de Valencia, Valencia,13-14 Noviembre 2010 
1. Dióxido de carbono (CO2) proveniente de la quema de combustibles fósiles y de biomasa, incendios forestales;

2. Óxido nitroso (N2O) del cultivo de arroz, producción pecuaria, residuos sólidos urbanos, emisiones fugitivas;

3. Metano (CH4) también del cultivo de arroz, producción pecuaria, residuos sólidos urbanos, emisiones fugitivas;

4. Hidrofluorocarbonos (HFCs) proveniente de la refrigeración, extinguidores, petroquímica, solventes en producción de espumas, aerosoles, producción y uso de halocarbonos;

5. Perfluorocarbonos (PFCs) de los refrigerantes, producción de aluminio, solventes, aerosoles, producción y uso de halocarbonos, $y$

6. El hexafluoruro de azufre (SF6) de los refrigerantes industriales, transformadores en redes de distribución eléctrica, producción de aluminio, magnesio y otros metales, producción y uso de halocarbonos. ${ }^{26}$

De estos datos se deduce que las TICs no sólo son parte del problema sino que cada año que pasa su contribución a las emisiones de $\mathrm{CO}_{2}$ es mayor, y presumiblemente seguirá aumentando. Dentro de este casi 3\%, una parte importante proviene del consumo energético de los data center.

En consecuencia las tecnologías de la información y de la comunicación son hoy una pieza fundamental en la lucha contra el cambio climático y en pro de la sustentabilidad. Necesitamos una tecnología ambientalmente amigable, y como sostiene el director ejecutivo de la Asociación Argentina de Usuarios de la Informática y las Comunicaciones, Juan José Dell Acqua, la tecnología puede ayudar mucho a reducir gran parte de la contaminación con las herramientas que posee. El problema puede ser parte de la solución y podría contribuir a la reducción de 7,8 gigatoneladas de gases invernaderos de forma anual, lo que sería el equivalente a alrededor del $15 \%$ de las emisiones globales actuales y cinco veces más de las generadas por esas mismas tecnologías de aquí a $2020^{27}$.

En este marco aparecen las Tecnologías Verdes, Informática Verde, Green IT, Green Computing, referidas al uso eficiente de los recursos computacionales minimizando el impacto ambiental, maximizando su viabilidad económica y asegurando deberes sociales, desempeñando políticas de desarrollo sustentable, desarrollando productos informáticos ecológicos y promoviendo el reciclaje computacional

Conceptos de Ambiente, Derecho al Ambiente y Desarrollo Sustentable

\footnotetext{
${ }^{26}$ ONU Convención Marco de las Naciones Unidas sobre Cambio Climático Anexo A, 1992

${ }^{27}$ Op. Cit. En Nota 8
} 
La problemática ambiental entrelaza dos conceptos básicos: ambiente y desarrollo sustentable, comprendiendo el ambiente como un todo cuyos elementos interactúan con un grado de interdependencia proyectándose a niveles regionales y globales Esa comprensión sólo se puede alcanzar incorporando al sistema de derecho a la calidad de vida del ser humano como bien supremo de tutela (GÜIDI, 1998).

Podemos considerar al ambiente como la sistematización de fenómenos, procesos y valores, naturales, sociales y culturales que condicionan en un tiempo y espacio determinado la vida del hombre en sociedad y el desarrollo del resto de los organismos vivos y el estado de los elementos inertes, en una síntesis integradora y dialéctica de relaciones de intercambio del hombre con los diversos recursos naturales, agotables y no agotables en términos económicos (MOSSET ITURRASPE, 1999; IGLESIAS y MARTÍNEZ, 1997)

El ambiente, así entendido, se encuentra indisolublemente relacionado con el concepto de desarrollo sustentable y el de calidad de vida de la población. La cuestión ambiental atraviesa todas las disciplinas y categorías jurídicas siendo el objetivo final de la tutela jurídica del ambiente lograr el pleno reconocimiento de las nociones, principios e instituciones ambientales, cuyo abordaje desde la técnica jurídica excede la configuración de una nueva rama especializada. Sin embargo, hasta tanto se alcance este objetivo final se acepta la existencia del Derecho Ambiental como un estadio intermedio en el proceso gradual, continuo y permanente. ${ }^{28}$

Las consecuencias del descontrol de la contaminación ambiental tanto en países desarrollados como en vías de desarrollo, y la imposibilidad del disfrute y ejercicio de los derechos humanos en condiciones ambientalmente desfavorables, crearon la conciencia generalizada del íntimo vínculo existente entre derechos humanos y ambiente.

Así, la problemática ambiental como "derecho al ambiente" con posibilidad de ser ejercitado a nombre de cualquiera por formar parte de los denominados intereses difusos, ha irrumpido en el concierto internacional en el año 1972 en la Declaración de Estocolmo sobre Medio Ambiente Humano y ha sido desarrollado por la Carta Mundial de la Naturaleza del año 1982, la Declaración de Río sobre Medio Ambiente y Desarrollo del año 1992 y la Declaración de Johannesburgo del año 2002 (MARTíNEZ, LÓPEZ ALFONSÍN). Pero, no ha de olvidarse los instrumentos regionales (SABSAY, 2000), Carta Africana de Derechos del Hombre y de los Pueblos de 1981 y el Protocolo Adicional a la Convención Americana sobre Derechos Humanos. El reconocimiento del derecho a gozar de un ambiente sano y equilibrado, que conjuntamente con el derecho al desarrollo, a la paz, a la libre determinación de los pueblos, al patrimonio común de la humanidad, y, finalmente el mega derecho humano al desarrollo sustentable (PEÑA CHACÓN, 2003), constituyen la pléyade de derechos humanos de tercera generación, derechos de la solidaridad o derechos de la humanidad.

\footnotetext{
${ }^{28}$ MARTÍNEZ, Adriana Norma. Acerca de la Tutela Jurídica del Ambiente en: Desarrollo Territorial Sostenible, Instrumentos participativos para la acción, 1era. Edición, Neuquén : EDUCO, Universidad Nacional del Comahue, 2008, p. 35-42
} vol. 08, nº 04, Número Especial. Rio de Janeiro, 2015.pp. 2174-2208 
Diversos autores (IGLESIAS y MARTÍNEZ, 1997) afirman que, desde su temprana formulación se ha asistido al nacimiento de un derecho de cuarta generación, por cuanto, no sólo exige la concertada acción positiva de todas las fuerzas sociales en pos del logro de un objetivo común, sino que lo hace con miras a satisfacer las necesidades e intereses de las generaciones por venir considerando que existe una solidaridad de efectos diferidos

La sinergia del derecho al ambiente y del derecho al desarrollo ha dado lugar al nacimiento del mega derecho humano: derecho al desarrollo sustentable, entendiendo por tal a aquel tipo de desarrollo que satisface las necesidades de las generaciones presentes sin comprometer la capacidad de las generaciones futuras de satisfacer sus propias necesidades. (DRNAS de CLIMENT, 1998). Surge así con toda claridad que el derecho al ambiente se encuentra indisolublemente relacionado con el concepto de desarrollo sustentable y el de calidad de vida cuyo protagonista central es el ser humano de las generaciones presentes y futuras

Protección jurídica del Ambiente en el Sistema Jurídico Argentino

En virtud de la reforma constitucional, se incorpora, en el artículo 41 de la Ley Suprema, el derecho a un ambiente sano, equilibrado, apto para el desarrollo humano, el desarrollo sustentable aparece íntimamente ligado al derecho al ambiente, bajo la clara referencia al compromiso intergeneracional de preservación del ambiente para las generaciones presentes y futuras, como actividades productivas que satisfacen las necesidades presentes sin comprometer las de las generaciones futuras y del concepto de "desarrollo humano" al conceptualizarlo como "apto para el desarrollo humano "y en los incisos 17, 19 y 23 del artículo 75

Finalmente y completando la protección constitucional en materia ambiental mencionamos la regulación del amparo, en el artículo 43, aludiendo tanto a los "derechos que protegen el medio ambiente" como a los "derechos de incidencia colectiva en general." En consecuencia, el afectado, el defensor del pueblo y las asociaciones que propendan a esos fines reconocidas por ley se encuentran legitimados para interponer el amparo ambiental. ${ }^{29}$

Además la Corte Suprema admitió que el derecho del artículo 43 también puede ejercitarse tanto por la vía del amparo como por la acción declarativa ${ }^{30}$

\section{Tecnología verde, green computing, informática sustentable, economía verde, eco- eficiencia: definiendo términos}

\footnotetext{
${ }^{29}$ LÓPEZ ALFONSÍN, Marcelo; TAMBUSSI, Carlos El medio ambiente como derecho humano, Capitulo XII en GORDILLO, Agustín Derechos Humanos; 5a Edición; Capítulo XIII; Buenos Aires : Fundación de Derecho Administrativo.2005, p XIII-3 XIII-5

${ }^{30}$ AGUEERA Asociación de Grandes Usuarios de Energía Eléctrica de la República Argentina, LL, 1997-C, 322, con nota: Las asociaciones de usuarios y la defensa de los derechos de incidencia colectiva (Acción declarativa de inconstitucionalidad).
} vol. 08, nº. 04, Número Especial. Rio de Janeiro, 2015. pp. 2174-2208 


\section{Conceptos de Green Computing y de Informática Sustentable}

El término Green Computing, también conocido como Green IT, no posee una traducción oficial al español, pero se denomina indistintamente como Tecnología Verde o Informática Verde, término proveniente del francés L’Informatique Verte. Son métodos de la industria de la informática para reducir las emisiones de $\mathrm{CO}_{2}$ en la fabricación de computadoras y la reducción del consumo energético de los mismos y se refiere al uso eficiente de los recursos computacionales minimizando el impacto ambiental, maximizando su viabilidad económica y asegurando deberes sociales, logrando además reducir costes operacionales, aumentar los beneficios, adquiriendo una conciencia ambiental que de masificarse permitiría una mejor perspectiva de futuro al planeta

Se puede definir como un conjunto de métodos que reducen el impacto informático sobre el ambiente e incluso se considera el reciclaje de muchos de los componentes utilizados en estos procesos permitiendo que otras personas continúen obteniendo provecho de estas tecnologías, diseñadas para reducir costos.

Algunos autores franceses (CORNE, PORCHERON, GUY, PAVIA, 2009) definen: "La Informática Verde es la toma de conciencia de una dimensión medioambiental para el ciclo de vida (desde la selección hasta el reciclaje, pasando con la gestión diaria) de materiales, software y servicios ligados a los sistemas de información"31

Por su parte, MURUGESAN y CORDERO (2008) ${ }^{32}$, dos autores que abordaron recientemente el tema y específicamente han diseñado algunas definiciones coincidentes, señalan que realmente la computación verde es el estudio y la práctica de diseñar, fabricar, utilizar y disponer de las computadoras, servidores y subsistemas asociados de manera eficiente y eficaz con mínimo o ningún impacto sobre el ambiente. Entonces, la propuesta es no solamente trabajar en el último eslabón de la cadena, que sería el beneficio de una persona que saca provecho de un dispositivo electrónico para cumplir o desarrollar una actividad ya sea de tipo laboral o de tipo esparcimiento, sino que realmente las acciones deben ir mucho más atrás, desde la propia concepción del producto, desde su diseño, de su fabricación y por supuesto en las normas de la utilización

Orígenes y evolución del concepto

En 1975, el "Energy Policy Conservation Act", EPCA, de Estados Unidos, demandaba al Departamento de Energía crear programas de voluntariado con el fin de disminuir el consumo energético de aparatos eléctricos y electrónicos en el hogar.

El acto que protocolizó la fundación de Energy Star, el primer eco-sello sobre Green IT, fue propuesto en 1993 en la línea del EPCA, desarrollado por la Agencia de Protección Ambiental (EPA, por sus siglas en inglés) y diseñado para promover y reconocer la eficiencia energética de diversas tecnologías como computadoras,

\footnotetext{
${ }^{31}$ CORNE, Christian; PORCHERON, Adrien; GUY, Pénélope; PAVIA, James Green IT Les meilleures pratiques pour une informatique verte Francia : DUNOD, 2009

${ }^{32}$ MURUGESAN, San. ”Harnessing Green IT: Principles and Practices," IT Professional, Vol. 10, nº 1, p.24-33, enero/febrero 2008
} 
monitores y aires acondicionados. El objetivo era de censar más de 2000 productos dentro de los cuales, una de las características que se exigía a los constructores de PC's y monitores, era que debían consumir máximo 30 watts durante la fase de hibernación.

El suceso del eco-sello Energy Star y lo que muchos vimos aparecer al encender nuestros computadores a partir de 1993, se debe a esa decisión política.

Habiendo constatado que la administración americana era un comprador masivo de equipos informáticos, el gobierno americano decidió adquirir solamente material labelizado, es decir eco-sellado, Energy Star. Es así como una decisión de Bill Clinton fue el primer acto concreto, significativo y masivo de compromiso en el dominio de Green IT.

En Canadá, como en el resto de los países del norte, el concepto engloba nociones de limpieza o de recuperación; se corrigen errores o se trata de evitar repercusiones negativas sobre el ambiente. En los países que no han sufrido los embates de la contaminación industrial, las tecnologías verdes representan sobre todo un enfoque basado en la fabricación de un producto comercial, con una óptica no solamente económica, sino también ambiental, social y cultural.

Por su parte, la informática sustentable no sólo abarca el proceso de fabricación y reciclaje, sino que también cubriría procesos como el diseño de los componentes y el propio gasto energético derivado del uso de las tecnologías de la información y comunicación. Es importante destacar también que la informática sustentable y un mejor uso de la energía podrían, a su vez, ayudar a reducir las emisiones en otros sectores, como el de transporte y el industrial. Un diseño más verde y ecológico podría ser vital, por ejemplo, en el caso de los centros de procesamientos de datos, una de las partes de las ICT que más contamina

\section{Conceptos de Economía Verde, Organización Verde y de Eco-eficiencia}

En los últimos años ha tomado fuerza el concepto de organización verde, derivado del concepto de Economía Verde, que se reafirma a partir de Río +20, en el contexto del desarrollo sustentable y la erradicación de la pobreza, como uno de los instrumentos más importantes disponibles para lograr el desarrollo sostenible, aumentando la inclusión social, mejorando el bienestar humano y creando oportunidades de empleo y trabajo decente para todos, manteniendo al mismo tiempo el funcionamiento saludable de los ecosistemas de la Tierra. El documento final de la Cumbre - "El futuro que queremos"- hace un llamamiento a los gobiernos, a la sociedad civil y al sector privado para unirse, y cumplir con una serie de compromisos que tienen por objeto adaptar las economías nacionales y regionales a las limitaciones del planeta. 
Las discusiones sobre la economía verde sentaron las bases de una efectiva transición a una economía baja en carbono, eficiente en el uso de recursos, con los objetivos primarios de la creación de puestos de trabajo, crecimiento social, inclusión y, en última instancia, la erradicación de la pobreza.

En algunos países, la cuestión primordial es cómo una economía verde puede acelerar y ampliar la erradicación de la pobreza. En otros - por ejemplo en el Unión Europea, Japón y América del Norte, - se manifiesta en formas que reflejan imperativos nacionales tales como la eficiencia de los recursos y disociar el crecimiento económico de la huella ambiental. ${ }^{33}$.

Asimismo dispone que las políticas de economía verde, entre otras, deberán ser compatibles con el derecho internacional, respetar la soberanía nacional de cada país sobre sus recursos naturales, promover el crecimiento económico sostenido e inclusivo respetando los derechos humanos, tener en cuenta las necesidades de los países en desarrollo, fortalecer la cooperación internacional, contribuir a colmar la brecha tecnológica entre los países desarrollados y en desarrollo y reducir dicha dependencia

Además la economía verde mejorará la capacidad para gestionar los recursos naturales de manera sostenible con menos consecuencias negativas para el ambiente, el aprovechamiento de los recursos y reducirá los desechos. Finalmente, alienta a cada país a considerar la posibilidad de implantar políticas de economía verde de manera que se procure impulsar un crecimiento económico y la creación de empleos sostenidos, inclusivos y equitativos, en particular para las mujeres, los jóvenes y los pobres. ${ }^{34}$

En consecuencia una organización verde, es aquella organización que hace una contribución efectiva a la sustentabilidad del ambiente y actualmente se considera que una organización es verde cuando sus procesos y sus operaciones hacen una contribución eficiente para la protección del mismo. Asimismo, se ha buscado desarrollar un nuevo modelo que permita propiciar una cultura altamente sustentable y respetuosa del ambiente en lo que concierne a la gestión de los recursos naturales, al incremento de la eficiencia de la energía, a la reducción de las emisiones de gas carbono, al uso renovable de fuentes de energía, al incremento de la conservación del agua, al incremento en el desarrollo de productos y servicios verdes, al manejo de ambientes amigables para la operación del negocio, a la gestión de desperdicios y la utilización de tecnologías altamente limpias. Este conjunto de iniciativas para la gestión de organizaciones verdes se suele englobar en el concepto de Eco-eficiencia, un concepto presentado por ForFas, 2011, una organización irlandesa dedicada a promulgar y desarrollar iniciativas para la creación y sustentabilidad de organizaciones verdes.

El concepto de ecoeficiencia nace de la concepción global de los impactos ambientales de las diferentes fases del ciclo de vida de un producto, y de la voluntad de reducir los diferentes efectos ambientales negativos. Una

${ }^{33}$ RAMOS DE ARMAS, Federico. "Rio+20 Start of a Process" STEINER, Achim. "Making History" en Revista UNEP Our Planet. Rio+20: From Outcome to Implementation, p.5-8, febrero 2013.

${ }^{34}$ ONU Conferencia de las Naciones Unidas sobre Desarrollo Sostenible Río+20. A/CONF.216/L.1,2012, Río de Janeiro, p.1014,2012 
definición de ecoeficiencia es la siguiente: "Proporcionar bienes y servicios a un precio competitivo, que satisfaga las necesidades humanas y la calidad de vida, al tiempo que reduzca progresivamente el impacto ambiental y la intensidad de la utilización de recursos a lo largo del ciclo de vida, hasta un nivel compatible con la capacidad de carga estimada del planeta". World Business Council for Sustainable Development (WBCSD) ${ }^{35}$ La ecoeficiencia se halla estrechamente ligada al desarrollo sostenible ya que equivale a optimizar tres objetivos: crecimiento económico, equidad social y valor ecológico, siendo el principal medio a través del cual las empresas contribuyen al desarrollo sostenible y al mismo tiempo consiguen incrementar su competitividad. Este concepto significa añadir cada vez más valor a los productos y servicios, consumiendo menos materias primas, generando cada vez menos contaminación a través de procedimientos ecológica y económicamente eficientes y previniendo los riesgos El concepto de ecoeficiencia se veía como una solución integral que permitía a las empresas aumentar sus beneficios a la vez que reducía su impacto ambiental. Por lo tanto ganaban todos: las empresas y el medio ambiente.

Por su parte, United States Department of Agriculture, a partir del 2009, ha propuesto líneas de acción muy concretas para desarrollar iniciativas estratégicas para consolidar un modelo de organización verde desde el ámbito tecnológico, en especial lo relacionado con la reducción del carbono. Dentro de algunas de las normas concebidas en este plan se destacan, por ejemplo: la reducción de la intensidad energética en un 3\% anual hasta el final del año fiscal 2015 y / la reducción de hasta un 30\% hasta finales del año fiscal 2015, la búsqueda de energías alternativas para consumo, reducir la intensidad del consumo de agua en 2\% anual hasta el final del año fiscal 2015, o del $16 \%$ hasta finales del año fiscal $2015^{36}$.

Por lo tanto, lo que se busca es crear o impulsar estrategias, iniciativas y proyectos que busquen optimizar los procesos de la organización y a la vez, generar una sustentabilidad en materia de creación o de conformación de una organización verde. El rediseño de procesos organizacionales también es otro de los elementos que puede contribuir de manera significativa en la reducción del cambio climático y en la reducción de la emisión de carbono. Rediseñar procesos implica tratar de simplificar tareas dentro de un proceso específico, crear una conciencia de economía, de energía, hablando de energía no solo de tipo de consumo, sino también en el concepto de energía asociada a los aspectos humanos.

\section{CLASIFICACIÓN DE LAS NUEVAS TENDENCIAS EN TECNOLOGÍAS VERDES}

\footnotetext{
35 FUNDACIÓN FORUM AMBIENTAL. "Guía para la Ecoeficiencia" [Consulta: 1/06/2015] Disponible en: <http://www.forumambiental.org/pdf/guiacast.pdf>

36 BERNAL, Wilson. Ponencia Computación Verde / Green IT.2001 [Consulta: 2/06/2015] Disponible en: $<$ http://www.bionna.org/noticias/?p=19>
} 
Algunas de las tecnologías clasificadas como verdes, debido a que contribuyen a la reducción en el consumo de energía o emisión de dióxido de carbono, son:

\section{Desmaterialización de documentos: como ser: archivos digitales -oficinas sin papeles, factura electrónica}

Alvin Toffler, refiriéndose a los elementos básicos del mañana, dice: " En vez de estar culturalmente dominada por unos cuantos medios de comunicación de masas, la civilización de la tercera ola descansará sobre medios interactivos y desmasificados, introduciendo una imaginaría sumamente diversa y a menudo altamente despersonalizada dentro y fuera de la corriente cultural de la sociedad"37.(TOFFLER,1979:340)

BRESSAND_DISTLER (1986) ${ }^{38}$ también se refieren a la desaparición del papel, aludiendo al mercado electrónico, que implica un triple encuentro: el de las tecnologías de información, de una forma de organización (la de las redes) y de una lógica económica (la del mercado).

Por otra parte, sólo hace falta la observación cotidiana, para comprobar la certeza de tales anuncios. El documento electrónico se ha convertido en un aliado del ambiente. Desde que se empezó a utilizar sistemas como el intercambio electrónico de datos (en inglés Electronic Data Interchange o EDI) para el uso de transacciones comerciales, ha contribuido a un gran cambio el remplazar el uso de papel por el de medios electrónicos. La cultura que está generando el documento electrónico permite que todos los días se trabaje con mensajes de texto, mensaje de datos, correos electrónicos, que las transacciones sean soportadas por medios electrónicos; y que sin pensarlo con estas acciones se contribuya cotidianamente a no usar papel físico, que impacta negativamente en el ambiente.

En Argentina, en el 2001 se sancionó la Ley No 25.506 sobre firma digital, y posteriormente, su Decreto Reglamentario No 2628/2002, estableciendo la equivalencia funcional del documento digital y la firma digital con la firma manuscrita y documento escrito tradicional, y el uso de mensaje de datos con fuerza probatoria, como los mecanismos de autenticidad, integridad y confidencialidad que ofrecen, tomando como fuente la Ley Modelo de la Comisión de las Naciones Unidas para el Derecho Mercantil Internacional (UNCITRAL, por su sigla en inglés) sobre Comercio Electrónico de 1996, con las modificaciones de 1998 y la Ley Modelo de UNCITRAL sobre Firma Digital o Firma Electrónica Refrendada de 2002.

Otra especie del documento electrónico es el correo electrónico o email, que es fuente de manejo constante de información, y respecto del cual algunas empresas vienen aplicando lo que se puede denominar manejo ambiental del correo electrónico, incorporando mensajes automáticos como el siguiente: "No imprima

\footnotetext{
${ }^{37}$ TOFFLER, Alvin. La Tercera Ola. Barcelona: Plaza y Janés, 1979, p. 340

${ }^{38}$ BRESSAND, Albert; DISTLER, Catherine. El Mundo del Mañana Buenos Aires: Editorial Planeta, 1986, p.174 vol. 08, nº. 04, Número Especial. Rio de Janeiro, 2015.pp. 2174-2208
} 
este correo electrónico sino es estrictamente necesario", en sus emails. Sin embargo, en algunos espacios se habla de uso racional y proporcional de tecnologías, donde se puede relacionar la informática y el ambiente más exactamente con el correo spam. Este tipo de correo ha generado muchas controversias y estudios en cuanto a la huella de carbono del spam.

\section{Optimización del papel}

La producción y consumo de papel tienen un fuerte impacto ambiental y social sobre el planeta. La industria papelera y de celulosa ocupa el quinto lugar del sector industrial en consumo mundial de energía, y utiliza más agua por cada tonelada producida que cualquier otra industria. También, la industria pastero-papelera se encuentra entre los mayores generadores de contaminantes del aire y del agua, así como gases que causan el cambio climático. La fabricación y consumo de papel y el futuro de los bosques están estrechamente unidos, aunque frecuentemente la cantidad de madera empleada en la fabricación de pastas vírgenes se infravalora al no contabilizarse los consumos de restos y residuos de aserraderos. Lo cierto es que cerca del $40 \%$ de toda la madera talada para usos industriales en el mundo se destinó a la producción de papel: el 25\% son para la industria del papel, mientras que el otro $15 \%$ restante procede de subproductos de otros sectores (aserrío, fabricación de tableros, etc.). ${ }^{39}$

Una de las eco-prácticas recomendadas se basa en la centralización de los sistemas de impresión, (incluido faxes, copiadora, escáneres, entre otros) ya que consume mucho menos energía un solo equipo que varios equipos distribuidos en varios puestos de trabajo. Además los usuarios deben esta concientizados de la verdadera necesidad antes de pulsar el botón 'imprimir'. Una correcta administración del flujo de documentos de todo tipo en una organización basada en una gestión documental aplicando principios de racionalización y economía permite la recuperación de información cuando se necesite, determinar el tiempo que los documentos deben guardarse, eliminar los que ya no sirven y asegurar la conservación indefinida de los más valiosos al tiempo que se reducen costes en tiempo y en dinero y se colabora con el ambiente.

En algunos países ya se ensayan buenas prácticas en la gestión de la Administración pública. El concepto de oficinas "cero papel" u "oficina sin papel" se relaciona con la reducción sistemática del uso del papel mediante la sustitución de los flujos documentales en papel por soportes y medios electrónicos. Es una consecuencia de la administración electrónica que se refleja en la creación, gestión y almacenamiento de documentos de archivo en soportes electrónicos, gracias a la utilización de Tecnologías de la Información y las Comunicaciones.

\footnotetext{
${ }^{39}$ GREENPEACE. Guía para un consumo responsable de productos forestales El papel Cómo reducir el consumo y optimizar el uso y reciclaje de papel; Barcelona: Greenpeace, 2004, p.7 
La oficina "Cero Papel" no concibe la eliminación radical de los documentos en papel. La experiencia de países que han adelantado iniciativas similares ha demostrado que los documentos en papel tienden a convivir con los documentos electrónicos en la medida que el Estado no puede negar a los administrados la utilización de canales presenciales o en papel. Una forma de representar el paso de modelos basados en papel a electrónicos es el siguiente: Fase 1: Uso exclusivo de papel, administración manual. Fase 2: Uso exclusivo de papel, administración apoyada en aplicaciones de tecnología. Fase 3: Combinación de papel con documentos digitalizados, administración apoyada en aplicaciones de tecnología. Fase 4: Uso exclusivo de documentos electrónicos, administración exclusiva mediante aplicaciones de tecnología. En todo este proceso es requisito indispensable la adecuada aplicación de los principios de gestión documental, que garanticen la autenticidad, fiabilidad, inalterabilidad y disponibilidad de la información bajo las condiciones y durante el tiempo que las normas vigentes lo requieran. ${ }^{40}$

\section{Reciclaje de equipos}

La reducción de la brecha digital, a través de la promoción del uso de las TIC como herramientas del desarrollo, implica un crecimiento de residuos electrónicos al final de la vida útil de los equipos, cuyas implicaciones para el ambiente se deben tomar en cuenta. A pesar de los beneficios innegables de las TICs, no se debe olvidar la contaminación ambiental que puede causar si no se dispone de una estrategia de gestión sustentable de residuos electrónicos

Teniendo en cuenta que la mayoría de estos equipos tienen un tiempo de vida relativamente corto, la cantidad de componentes tóxicos que se generan cuando estos terminan en vertederos son una fuente directa de contaminación de la tierra y el agua; para ello se debe contar con una metodología clara de reciclaje del equipo y su tratamiento sustentable. Sustancias químicas y metales pesados como berilio, cromo, cadmio, arsénico, selenio, antimonio, mercurio y plomo contenidos en aparatos eléctricos y/o electrónicos son altamente peligrosos y necesitan un depósito especial para no contaminar e intoxicar el ambiente. Tanto las empresas dentro de sus trabajos diarios como las empresas proveedoras de los mismos deben estar atentas a lo que ocurre cuando estos equipos dejan de ser útiles dentro de la empresa.

Los países desarrollados han llevado a cabo una serie de acciones que tienen como objetivo proteger el ambiente y recuperar los materiales de valor de los residuos, o desechos electrónicos (RE), así como resaltar el negocio del reciclado por la alta cantidad de minerales presentes en los mismos Los equipos electrónicos contienen hasta 17 metales preciosos incluyendo oro, plata y cobre, los cuales siguen teniendo un valor

${ }^{40}$ COLOMBIA Ministerio de Tecnologías de la Información y las Comunicaciones. Guía 1 Cero Papel Buenas Prácticas para reducir el Consumo de Papel [Consulta: 4/6/2015] Disponible en Web http://programa.gobiernoenlinea.gov.co/apc-aafiles/Cero_papel/guia-1-cero-papel.pdf, p.8 
económico significativo cuando los aparatos caen en desuso. Si bien el reciclaje de los residuos electrónicos es considerado como un ámbito de negocio lucrativo, en muchos países faltan tanto reglamentaciones específicas como iniciativas empresariales. El reacondicionamento y el reciclaje de residuos electrónicos son dejados al sector informal, lo que expone a miles de recicladores a graves riesgos de salud por falta de conocimiento de los peligros causados por la incineración abierta de desechos, entre otros tratamientos Latinoamérica recién está asumiendo estas responsabilidades y desde hace unos pocos años surgen iniciativas, donde participan sectores públicos y privados, con la intención de desarrollar estrategias para el tratamiento de estos aparatos al final de su vida útil.

En esta misma línea se están generando en la región políticas de promoción del adecuado tratamiento de los RE. Si bien se vinculan a todos los aparatos electrónicos, muchas de ellas han tomado como referencia a los computadores Aunque los RE incluyen una amplia y creciente gama de aparatos eléctricos y electrónicos (AEE) los objetivos de los proyectos y de las principales iniciativas latinoamericanas en relación con esta área se enfocan en los residuos de los computadores

No hay mayores dudas sobre el hecho que a los RE que se generan directamente en las fábricas les son aplicables las reglas de los residuos industriales. Pero el mayor porcentaje proviene directamente de los usuarios y no les deberían ser aplicables las reglas de los residuos domiciliarios debido a su toxicidad y peligrosidad. No es conveniente que su disposición final se realice en basural o como relleno sanitario, pero es la tendencia natural del usuario disponerlo con el resto de sus desechos.

En cuanto a la normativa vigente, a nivel internacional, se debe hacer referencia al Convenio de Basilea sobre el Control de los Movimientos Transfronterizos de los Desechos Peligrosos y su Eliminación de 1989 y a la Directiva Europea 2002/96/CE que es una de las primeras normas especiales sobre el tratamiento de los residuos de los aparatos eléctricos y electrónicos (RAEE). Se basa, esencialmente, en determinar lineamientos generales y especificar metas y responsabilidades para todos los países de la Unión. Se establecen como objetivos principales de esta directiva la prevención en la producción de RAEE, la reutilización, el reciclaje y otras formas de valorización de dichos residuos a fin de reducir al máximo su eliminación, así como el mejoramiento de la protección del ambiente y de la salud de todos aquellos que intervienen en el ciclo de vida de los aparatos eléctricos y electrónicos

Conforme al artículo 3 Directiva Europea 2002/96/CE, se consideran Aparatos Eléctricos y Electrónicos (AEE) "todos los aparatos que para funcionar debidamente necesitan corriente eléctrica o campos electromagnéticos, y los aparatos necesarios para generar, transmitir y medir tales corrientes y campos pertenecientes a las categorías indicadas en el anexo I A y que están destinados a utilizarse con una tensión nominal no superior a 1.000 voltios en corriente alterna y 1.500 voltios en corriente continua" Aunque los RE 
incluyan una amplia y creciente gama de aparatos eléctricos y electrónicos, AEE, la Directiva distingue diez categorías de $\mathrm{RE}^{41}$

El reciclaje, lo define como: "El reprocesado de los materiales de los residuos, dentro de un proceso de producción, para su finalidad inicial o para otros fines"

Uno de los temas clave es la ausencia de políticas e iniciativas que asuman la prevención del posible impacto negativo sobre el ambiente, producto del rápido aumento de computadores en desuso en Latinoamérica. Para aproximarse a esta temática se requiere conocer el proceso de producción inversa, desde su consumo hasta la disposición final de estos aparatos. De esta forma se identifican los pasos necesarios que guían el desarrollo que un aparato debe tomar para tener un conveniente tratamiento sustentable.

La aplicación de la responsabilidad extendida del productor - REP -, explicada en el punto 2, exige que el productor no sólo respete las normas de calidad establecidas para la generación de sus productos, sino que asuma la responsabilidad por el impacto producido luego de terminar su ciclo de vida útil.

Sin embargo, en Latinoamérica hay diversas circunstancias para que esto no sea así y la figura del productor es más bien borrosa e imprecisa. El parque de los productos electrónicos, específicamente los computadores, está compuesto en un volumen significativo por los equipos clonados, es decir aparatos que han sido ensamblados y que no tienen un nombre o una marca de producción asignada. Por consiguiente, el 'productor' no se hace responsable del destino final de su vida útil. También se encuentra la figura del donante internacional, con el fin de reducir la brecha digital se han transferido computadores donados desde países industrializados.

En Argentina, en 2011, el Congreso de la Nación trató el denominado proyecto de Ley de Gestión de Residuos de Aparatos Eléctricos y Electrónicos, el “Proyecto de Ley de RAEE”, el cual contó con media sanción del Senado, pero la ley fue demorada en la Cámara de Diputados por falta de tratamiento luego de su giro desde la Cámara alta. El 12 de julio del 2012 reingresó el mismo proyecto, siempre encuadrándose en la figura de ley de presupuestos mínimos. Fue aprobado por la Cámara de Diputados de la Nación, pero perdió estado parlamentario y se volvió a presentar, el 18 de septiembre del 2013 ante la Cámara de Senadores, sin llegar a sancionarse. La Provincia de Buenos Aires, desde el 2011, está vigente la Ley No 14321 para la gestión sustentable de Residuos de Aparatos Eléctricos y Electrónicos, RAEEs, según lo preceptuado en el artículo 41 de la Constitución Nacional, y el artículo 28 de la Constitución Provincial; en concordancia con lo establecido por el Convenio de Basilea, ratificado mediante Ley Nacional № 23.992 y las Leyes Provinciales No 11.720, Residuos Especiales y 13.592 Residuos Sólidos Urbanos.

\footnotetext{
${ }^{41}$ Ver en: http://europa.eu/legislation_summaries/environment/waste_management/121210_es.htm

${ }^{42}$ UNIÓN EUROPEA Directiva 2002/96/CE del Parlamento Europeo y del Consejo, del 27 de enero de 2003, sobre residuos de aparatos electrónicos o eléctricos, L.37, p.24-39, 13/2/2003
} 
En la Ciudad Autónoma de Buenos Aires se dictó la Ley No 2807/08 la cual establece medidas para la Gestión de Aparatos Electrónicos en Desuso del Poder Ejecutivo de la Ciudad Autónoma de Buenos Aires. Sin embargo solo se refiere a la cuestión en el ámbito del sector público y es incompleta

\section{Teletrabajo}

Teletrabajo y teleconferencia son dos de los métodos de trabajo de manera remota que aportan grandes beneficios en cuanto a finanzas y al ambiente. El concepto de teletrabajo nace en Estados Unidos de Norteamérica, en el año 1973, a partir de la crisis del petróleo, para reducir el traslado de trabajadores a las oficinas, reemplazándolo por el traslado de la información necesaria para que el trabajador realice sus tareas desde su casa o centro de teletrabajo próximo a su domicilio. El teletrabajo es una modalidad de trabajo, que viene desarrollándose como una alternativa laboral, que se manifiesta creciendo con el uso de las TICs, a distancia donde el sitio de trabajo puede ser: en el hogar del trabajador u otros espacios que no sean el domicilio de la organización para la cual se trabaje. Adoptando estas medidas se puede ayudar a disminuir la emisión de gases de efecto invernadero, ya que cada vez que se realizan viajes tanto por medios aéreos como terrestres se contribuye a aumentar el consumo de carburantes que además con el tiempo aumentan cada vez más de precio, por lo tanto se ahorran en este sentido importantes cantidades de dinero destinadas a viajes.

En cuanto a su conceptualización, no hay una única definición de Teletrabajo:

1. Al analizar más de 50 definiciones de teletrabajo, DI MARTINO-WIRTH, muestran que comparten tres conceptos básicos: organización, localización y tecnología. Más del 60\% de las definiciones se basan en una combinación de al menos dos de esos conceptos: "un trabajo efectuado en un lugar donde, apartado de las oficinas centrales o de los talleres de producción, el trabajador no mantiene contacto personal alguno con sus colegas, pero está en condiciones de comunicarse con ellos por medio de las nuevas tecnologías"43. ( DI MARTINO-WIRTH, 1990:530)

2. Desde el año 2005 la OIT lo hace de la siguiente manera "Trabajo a distancia (incluido el trabajo a domicilio) efectuado con auxilio de medios de telecomunicación y/o de una computadora”44

\section{Virtualización}

La virtualización que es un proceso por el cual se pueden crear varios sistemas operativos independientes ejecutándose en la misma máquina. Esto implica hacer que un recurso físico, como un servidor, un sistema

\footnotetext{
${ }^{43}$ DI MARTINO, Vittorio; WIRTH, Linda. “Telework: A new way of working and living”. International Labour Review, V. 129, N.5, 1990, p.530.

${ }^{44}$ OIT, Tesauro http://www.ilo.org/public/libdoc/ILO-Thesaurus/spanish/ 
operativo o un dispositivo de almacenamiento, aparezca como si fuera varios recursos lógicos a la vez, o que varios recursos físicos, como servidores o dispositivos de almacenamiento, aparezcan como un único recurso lógico. Esta tecnología permite la separación del hardware y el software, y, a su vez, consiste en la utilización de un software para posibilitar que un recurso físico pueda ejecutar múltiples máquinas virtuales aisladas con sus correspondientes sistemas operativos, simultáneamente. El Alojamiento web en servidores virtuales es uno de los marcos en los que encontramos habitualmente usos de la virtualización, es decir en las empresas de hosting.

\section{Data-Center Optimization - Optimización de Centro de Datos}

Al hablar de optimizar un centro de datos, el análisis apunta a qué tan buena es la operación en cuanto al consumo eléctrico directo por la alimentación de los servidores, y el total de energía gastada en otros aspectos, tales como enfriamiento, iluminación, etc. El gasto de energía en enfriamiento, llega a representar una cantidad equivalente a lo consumido directamente por los servidores.

En general, el potencial de ahorro de energía en los centros de datos y las salas de servidores es muy elevado y en muchos casos puede superar el 50\%, dependiendo de la tecnología informática y de las infraestructuras específicas de cada caso. Dentro del mejor uso de la tecnología incluyen los siguientes puntos: optimización en el uso de la energía, uso de materiales menos contaminantes, reducción sustancial del espacio físico y optimización en la gestión de los recursos ${ }^{45}$

\section{Cloud Computing}

La idea del Cloud Computing, término inglés, denominado en español como cómputo en la nube no es realmente nueva; se ha venido desarrollando y discutiendo desde hace muchos años referido al uso del Internet. Esta idea o término surge a partir de que los diagramas de flujo de red de los ingenieros o informáticos empezaron a mostrar a "Internet" mediante el dibujo de una nube. Estos diagramas de red contenían una nube como punto medio entre computadoras interconectadas a la misma red de redes. Toda esa zona de interconexión y flujo de información es lo que se conoce como "ciberespacio" o Internet, un entorno virtual e intangible, un gran canal de telecomunicación.

El término de "cómputo en la nube" ha sido definido por una de las instituciones de mayor reconocimiento en torno a las tecnologías: el Instituto Nacional de Estándares y Tecnología (NIST, por sus siglas en inglés), como: "El cómputo en la nube es un modelo que permite el acceso ubicuo, conveniente y bajo demanda de red a un conjunto de recursos informáticos configurables (por ejemplo, redes, servidores,

\footnotetext{
${ }^{45}$ UNIÓN EUROPEA Programa Energía Inteligente para Europa IT e Infraestructura energéticamente eficiente para centro de datos y sala de servidores PrimeEnergyIT Project, Viena, 2011, p. 3
} 
almacenamiento, aplicaciones y servicios) que puedan ser rápidamente proveídos con esfuerzos mínimos de administración o interacción con el proveedor de servicios. Este modelo en la nube promueve la disponibilidad y se compone de cinco características esenciales, tres modelos de servicios y cuatro modelos de implementación". $(\text { NIST, 2011:2) })^{46}$

Así, el cómputo en la nube es un modelo de servicios de TIC para el acceso, la asignación, el control y la optimización de los recursos, entendida como una puesta a disposición de recursos para el disfrute del usuario en diversas modalidades de servicio e implementación.

Por su parte Téllez Valdés lo define como "el ecosistema de recursos tecnológicos de la información y la comunicación, que ofrece servicios escalables, compartidos y bajo demanda en diferentes modalidades y a diversos usuarios a través de Internet." (TÉLLEZ VALDÉS, 2013:5)47

\section{Grid Computing}

Las tecnologías grid permiten que los ordenadores compartan a través de Internet u otras redes de telecomunicaciones no sólo información, sino también poder de cálculo (grid computing) y capacidad de almacenamiento (grid data). Es decir, en el grid no sólo se comparten contenidos, sino también capacidad de procesamiento, aplicaciones e incluso dispositivos totalmente heterogéneos (sensores, redes, ordenadores, etc.).

El término grid computing o computación en malla, viene a raíz de la analogía con la red eléctrica (electric power grid): nos podemos enchufar al grid para obtener potencia de cálculo sin preocuparnos de dónde viene al igual que hacemos cuando enchufamos un aparato eléctrico. Este innovador paradigma de computación distribuida es propuesto por Lan Foster y Carl Kesselman a mediados de los años 90, como una revolucionaría técnica para resolver problemas complejos entre diversas organizaciones optimizando costes y tiempo

En la computación "tradicional" basada en sistemas centralizados una organización tenía que utilizar sus propios recursos, empleando para ello grandes y costosos servidores con una enorme potencia de cálculo. En cambio, en la computación grid intervienen varias organizaciones, cada una con sus propios recursos computacionales La infraestructura grid integra un motor de búsqueda que no sólo encontrará los datos que el usuario necesite, sino también las herramientas para analizarlos y la potencia de cálculo necesaria para utilizarlas. El

\footnotetext{
${ }^{46}$ MELL, Peter; GRANCE, Timothy The NIST definition of Cloud Computing Recommendations of the National Institute of Standards and Technology, Gaithersburg MD: NIST Special Publication 800-145.p.2 En ingles "Cloud computing is a model for enabling ubiquitous, convenient, on-demand network access to a shared pool of configurable computing resources (e. g., networks, servers, storage, applications, and services) that can be rapidly provisioned and released with minimal management effort or service provider interaction. This cloud model promotes availability and is composed of five essential characteristics, three service models, and four deployment models".

${ }^{47}$ TÉLLEZ VALDÉS, Julio. Lex Cloud Computing Estudio del Cómputo en la nube en México, México : Universidad Nacional Autónoma de México, Instituto de Investigaciones Jurídicas, 2013, p. 5
} vol. 08, nº. 04, Número Especial. Rio de Janeiro, 2015.pp. 2174-2208 
objetivo final del grid es poder utilizar recursos remotos que nos permitan realizar tareas que no podríamos abordar en nuestra máquina o centro de trabajo.

Puesto que los recursos que son compartidos pertenecen a personas muy distintas, la seguridad es esencial, y se centra en los siguientes aspectos: política de accesos, autenticación y autorización ${ }^{48}$

\section{CONCLUSIÓN}

El concepto de informática verde ha impulsado la conciencia de muchas grandes empresas a desarrollar productos que sean "eco friendly" o amigables con el ambiente. La responsabilidad ambiental es compromiso de todas las disciplinas; y ante la magnitud de los riesgos al cual nos enfrentamos, comienza a imponerse en el cuidado de todas las personas, empresas, consumidores, Estados y organizaciones no gubernamentales, una actitud de anticipación que identifique las vías contaminantes, favoreciendo las tecnologías que aumenten la productividad de los recursos conforme al principio de selección sostenible de tecnologías. A su vez, se está ante tecnologías preventivas, cuyo objetivo es evitar la contaminación ambiental y a las de depuración, que buscan el tratamiento de los contaminantes ya formados La tecnología impacta directamente en el ambiente en que vivimos y al actuar como una empresa socialmente responsable, se puede obtener importantes reducciones en consumo de energía. Es el momento ideal para que los empresarios y ejecutivos conozcan más sobre el tema y empiecen a extenderlo en sus industrias. Existen diferentes maneras en las que tanto las empresas, como los consumidores, pueden involucrarse en el concepto de la tecnología verde. Lo primero es conocer sus pilares: la educación, el diseño y la administración. La educación, es un elemento clave que sensibiliza a los empleados que están en contacto directo con la tecnología sobre sus repercusiones al ambiente Además las empresas, las escuelas y los organismos oficiales pueden contribuir con campañas de concientización dirigidas a todas las personas permitiéndoles diferenciar qué tecnologías deben superarse, adoptarse, o ignorarse en pro de mejorar su calidad de vida causando el menor impacto posible al ambiente y la adecuada administración contribuye con el tema en acciones como el ahorro de hojas de papel y de energía, entre otras

Finalmente la utilización de computadoras eficientes es una solución viable, capaz de satisfacer sin problemas las necesidades de cualquier estación de trabajo, ofreciendo un equilibrio entre el rendimiento y consumo, ahorrando energía sin sacrificar capacidades, reduciendo drásticamente los costes de electricidad, beneficiando económicamente a hogares, empresas públicas y privadas, además de disminuir la generación de electricidad por parte de los países, limitando el uso de elementos fósiles y medios contaminantes

\footnotetext{
${ }^{48}$ MILLÁN TEJEDOR, Ramón Jesús “Grid Computing” Manual Formativo No 43. Editorial: ACTA, p. 17-22, 2007 vol. 08, nº. 04, Número Especial. Rio de Janeiro, 2015.pp. 2174-2208
} 


\title{
THE NEW XXI CENTURY ECONOMY: ANALYSIS OF THE IMPACTS OF INFORMATICS IN THE ENVIRONMENT. CURRENT TRENDS IN GREEN COMPUTER TECHNOLOGIES, A COMMITMENT TO SUSTAINABILITY
}

\begin{abstract}
Major technological advances in recent decades have generated profound social and organizational changes in the field of information and communications that affect our lives. The widespread use of computers, the proliferation of computer networks and the development of new technologies of information and communication, called ICT changed the way we communicate and transformed the economy and culture forever, originating an economic and social system in which the generation, processing and distribution of knowledge and information are the main source of productivity, power and prosperity. Informatics and industry in general have spared no effort to develop rapidly, but in most cases, at the expense of environmental degradation. However, ICTs can be an ally in the fight against climate change through processes called Green Technologies, which fall within the concept of green economy context of sustainable development, according to the final document of Rio +20 . This work details the impact of information technology in different fields and describe, in general terms, each computer ecological methods and products.
\end{abstract}

Keywords: New Economy - Information Society - Environment - Sustainable Development - Green IT

\section{REFERENCIAS BIBLIOGRÁFICAS}

AGUEERA. Asociación de Grandes Usuarios de Energía Eléctrica de la República Argentina, LL, 1997-C, 322, con nota: Las asociaciones de usuarios y la defensa de los derechos de incidencia colectiva (Acción declarativa de inconstitucionalidad).

ATSDR. Agencia para Sustancias Tóxicas y el Registro de Enfermedades. Reseña Toxicológica del Berilio. Atlanta, GA: Departamento de Salud y Servicios Humanos de EE. UU., Servicio de Salud Pública, 2002, 8 p.

BACHER, Silvia. "La verdadera brecha digital", Diario La Nación, Sección Opinión 6/11/2001, Buenos Aires[Consultado el 16/3/2015] Disponible en: <http://www.lanacion.com.ar/349072-la-verdadera-brechadigital>

BERNAL, Wilson. Ponencia Computación Verde / Green IT.2001 [Consulta: 2/06/2015] Disponible en: http://www.bionna.org/noticias/?p=19

BRESSAND, Albert; DISTLER, Catherine. El Mundo del Mañana Buenos Aires: Editorial Planeta, 1986, 250 p.

CASTELLS, Manuel. "La Ciudad de la Nueva Economía”. Revista La Factoría, Barcelona, Año XV, No 12 Junioseptiembre 2000.

La Galaxia Internet, España: Areté, 2000, 302 p.

CORNE, Christian; PORCHERON, Adrien; GUY, Pénélope; PAVIA, James. Green IT Les meilleures pratiques pour une informatique verte. Francia: DUNOD, 2009, 223p. 
CMSI. Cumbre Mundial de la Sociedad de la Información Declaración de Principios. "Construir la Sociedad de la Información: un desafío global para el nuevo milenio” Documento WSIS-03/GENEVA/4-S, Ginebra 2003 Túnez 2005, 12 de mayo de 2004, 9 p.

DI MARTINO, Vittorio; WIRTH, Linda. Telework: A new way of working and living. International Labour Review, V. 129, N.5, p. 529-564, 1990

FARIÑA, Clara; GUARÁS, M. Daniela; HUYKMAN, Natalia; PANIZZA, Amalia; PASCALE, Carla. "Huella de Carbono: Un Tema Insoslayable". Revista Alimentos Argentinos Buenos Aires: Ministerio de Agricultura, Ganadería y Pesca de la Nación Argentina, no 52, p.13-15, noviembre 2011

FUNDACIÓN FORUM AMBIENTAL. Guía para la Ecoeficiencia [Consulta: 1/06/2015] Disponible en: http://www.forumambiental.org/pdf/guiacast.pdf, $79 \mathrm{p}$.

COLOMBIA. Ministerio de Tecnologías de la Información y las Comunicaciones. Guía 1 Cero Papel Buenas Prácticas para reducir el Consumo de Papel [Consulta: 4/6/2015] Disponible en Web http://programa.gobiernoenlinea.gov.co/apc-aa-files/Cero_papel/guia-1-cero-papel.pdf, 17 p.

GREENPEACE. Gúa para un consumo responsable de productos forestales. El papel Cómo reducir el consumo y optimizar el uso y reciclaje de papel. Barcelona: Greenpeace, 2004, 20 p.

LÁREZ, Jesús; ABAFFY, Carlos. Las TIC y la Brecha Digital. 2da. Jornada de Ingeniería Informática Tecnología con sentido social, Guayana, Venezuela: UCAB, 2009.

LÓPEZ ALFONSÍN, Marcelo; TAMBUSSI, Carlos. El medio ambiente como derecho humano, Capitulo XII en GORDILLO, Agustín. Derechos Humanos; 5a Edición; Capítulo XIII; Buenos Aires : Fundación de Derecho Administrativo.2005, 359p.

MANERO ALFERT, Rogelio; MICHEVA, Lilian.; PETKOVA, Iveta. "Respuestas fisiológicas de hombres y mujeres a diferentes cargas de trabajo", Revista Cubana de Investigaciones Biométricas, Cuba, Vol. 3, p.11-21, enero/abril 1984

MARTÍNEZ, Adriana Norma. "Acerca de la Tutela Jurídica del Ambiente" en: Desarrollo Territorial Sostenible, Instrumentos participativos para la acción, lera. Edición, Neuquén : EDUCO, Universidad Nacional del Comahue, 2008, p.35-42

MELL, Peter; GRANCE, Timothy. The NIST definition of Cloud Computing Recommendations of the National Institute of Standards and Technology, Gaithersburg MD: NIST Special Publication 800-145, 7 p.

MILLÁN TEJEDOR, Ramón Jesús. “Grid Computing” Manual Formativo № 43. Editorial: ACTA, p. 17-22, 2007

MONTEVERDE, Federico. E-waste y su incorporación en la agenda gubernamental e internacional en UNESCO Plataforma Regional de Residuos electrónicos para América Latina RELAC. Los residuos electrónicos: Un desafío para la Sociedad del Conocimiento en América Latina y el Caribe. Montevideo: UNESCO RELAC, 2010, $251 \mathrm{p}$. 
MUÑOZ GINER, Javier; ROJAS RINCÓN, Yuresky. "Nuevas tendencias en tecnologías verdes -Green IT para la Gestión en Organizaciones” II Congreso Iberoamericano SOCOTE - Soporte al Conocimiento con la Tecnología- y VII Congreso SOCOTE Universidad Politécnica de Valencia, Valencia,13-14 Noviembre 2010

MURUGESAN, San. "Harnessing Green IT: Principles and Practices" IT Professional, Vol. 10, no 1, p. 24- 33, enero/febrero 2008

OECD. Organization for Economic Cooperation and Development. Understanding the digital divide, Paris: OECD Digital Economy Papers, n 49, 2001, 33 p.OIT, Tesauro http://www.lo.org/public/libdoc/ILOThesaurus/spanish/

ONU. Conferencia de las Naciones Unidas sobre Desarrollo Sostenible Río+20.A/CONF.216/L.1,2012, Río de Janeiro, septiembre 2012, $60 \mathrm{p}$.

ONU. Convención Marco de las Naciones Unidas sobre Cambio Climático Anexo A, 1992, 25 p.

PALLARES, José Hidalgo. "Brecha digital: la tecnología en la Argentina es cara y atrasada" Diario La Nación. Buenos Aires: 23/03/2014

PUCKETT, Jim; BYSTER, Leila; WESTERVELT, Sarah; GUTIERREZ, Richard; DAVIS, Sheila; HUSSAIN, Hasma; DUTTA. Madhumitta Exporting Harm: The High-tech Trashing of Asia Seattle: BAN, SVTC 2002, 54 p.

RAMOS DE ARMAS, Federico. "Rio+20 Start of a Process" en Revista UNEP Our Planet. Rio+20: From Outcome to Implementation, p. 5-6. febrero 2013

RECYCLA, CHILE. Residuos electrónicos (E-WASTE), la nueva basura del siglo XXI. Una Amenaza-Una Oportunidad. Santiago de Chile: RECYCLA, Chile, Fundación Casa de la Paz, 2007, 74 p.

RIFKIN, Jeremy. La Era del Acceso: La Revolución de la Nueva Economía, Barcelona: Paidós, 2000, 161 p.

SILVA, Uca. Los residuos electrónicos (RE) en la Sociedad de la Información en Latinoamérica En UNESCO. Plataforma Regional de Residuos electrónicos para América Latina RELAC. Los residuos electrónicos: Un desafío para la Sociedad del Conocimiento en América Latina y el Caribe. Montevideo: UNESCO RELAC, 2010,251 p.

SPOTA, Alberto. "Globalización, integración y derecho constitucional" en Revista La Ley, 22/2/99, Buenos Aires

STEINER, Achim. "Making History" en Revista UNEP Our Planet. Rio+20: From Outcome to Implementation, p. 7-8, febrero 2013, "Tecnología para cuidar el Medio Ambiente" Revista Claves 21 Ambiente y Desarrollo Sustentable [Consulta: 20/05/2015] Disponible en: http://claves21.com.ar/tecnologia-verde-herramientaspara-cuidar-el-medio-ambiente/

TÉLLEZ VALDÉS, Julio. Lex Cloud Computing Estudio del Cómputo en la nube en México, México: Universidad Nacional Autónoma de México, Instituto de Investigaciones Jurídicas, 2013, 783 p.

TOFFLER, Alvin. La Tercera Ola. Barcelona: Plaza y Janés, 1979, 335 p. 
UIT. Unión Internacional de las Telecomunicaciones. Informe sobre el Desarrollo Mundial de las Telecomunicaciones 2003: Indicadores de Acceso para la Sociedad de la Información. Ginebra: UIT, 2003, 28 p.

UNESCO. Informe Mundial Hacia las Sociedades del Conocimiento, Ediciones UNESCO: París, 2005, ISBN 92-3-304000-3, 240 p.

UNIÓN EUROPEA. Directiva 2002/96/CE del Parlamento Europeo y del Consejo, del 27 de enero de 2003, sobre residuos de aparatos electrónicos o eléctricos. Diario Oficial de la Unión Europea, L.37, p.24-39, $13 / 2 / 2003$

Programa Energía Inteligente para Europa IT e Infraestructura energéticamente eficiente para centro de datos y sala de servidores PrimeEnergyIT Project, Viena, 2011,52 p.

Trabalho enviado em 10 de junho de 2015

Aceito em 02 de julho de 2015. 